\title{
The Effects of Diurnal Heat Stress in Dairy Heifer Calves
}

\section{DOI:10.31274/air.11927}

H. K. J. P. Wickramasinghe, Graduate Research Assistant; N. Stepanchenko, Graduate Research Assistant; M. J. Oconitrillo, Graduate Research Assistant; J. V. V. Silva, Graduate Research Assistant; B. M. Goetz, Graduate Research Assistant; M. A. Abeyta, Graduate Research Assistant; J. A. D. R. N. Appuhamy, Assistant Professor; Department of Animal Science, Iowa State University

\section{Summary and Implications}

The present study was conducted to examine how dairy heifer calves would respond to a heat stress bout in terms of growth relative to nutrient intake. Nine Holstein and 2 Jersey heifer calves $(n=11)$ were individually housed and enrolled in a study containing 3 experimental periods (P). Period 1 lasted $7 \mathrm{~d}$ during which baseline measurements were obtained. During period 2 (7 d), calves were subjected to diurnal heat stress (dHS) employed by maintaining barn temperature at $33^{\circ} \mathrm{C}\left(92^{\circ} \mathrm{F}\right)$ from 0900 to $2100 \mathrm{~h}$ and letting it be equilibrated with outside temperature $\left[24^{\circ} \mathrm{C}\left(75^{\circ} \mathrm{F}\right)\right]$ during the night. Follow-up measurements were made over 4 d (P3) immediately after dHS. Calves consumed $25 \%$ less feed during the day but compensated for it consuming more feed $(35 \%)$ in night during dHS. Despite DMI $(\mathrm{kg} / \mathrm{d})$ being similar between dHS and baseline, ADG and feed efficiency decreased significantly during dHS. These effects are likely consequence of nutrient repartitioning towards the activated immune system and away from productive processes (i.e., growth), as blood haptoglobin increased 3-fold during dHS. Nonetheless, calves exhibited compensatory growth concurrently with increased DMI and drinking water per unit of DMI immediately following dHS. Overall, dHS severely hampers growth and feed efficiency of dairy heifer calves despite unaltered DMI relative to baseline. Understanding nutrient partitioning in calves during and after heat stress could help mitigate the adverse effects and help calves effectively recover from heat stress.

\section{Introduction}

Animals experience environmentally induced hyperthermia ("heat stress") when heat gain from environment and internal metabolism surpass thermolytic capacity. Heat stress is one of the greatest challenges faced by both United States and global dairy industries today. Further, elevated ambient temperatures can be persistent over an entire summer or can occur in intense bursts for shorter periods of time as seen in Midwestern regions of the United
States. Even though there is relief from heat during the evening hours (diurnal pattern), intense surges of heat during the daytime can decrease animal performance and productive efficiency. Heat stress decreases production primarily by decreasing feed intake in farm animals. Further, it also decreases nutrient utilization efficiency and negatively affects reproduction performance of the animals. It is estimated that the economic burden arising from these complications of heat stress amount to more than $\$ 1.5$ billion in the US dairy industry alone, highlighting the importance of identifying amelioration strategies to implement on farm. Higher metabolic heat production and low surface area-tomass ratio make mature cows more susceptible to heat stress than other farm animals. On the contrary, young calves and growing heifers are more heat tolerant than mature cows owing to better heat dissipation capacity and lower ruminal and metabolic heat production. The majority of previous studies focus on heat stress in mature cows, however, there is evidence indicating there are significant short and long-term effects of hyperthermia in calves and heifers. For instance, heat stress has been shown to affect feed intake, feed conversion efficiency, and growth as a result of its direct effects on neuroendocrine, and immune systems in growing cattle. There is a need to better characterize the direct and indirect effects of dHS in dairy calves, thus, the objective of this study was to evaluate the effects of diurnal heat stress on production and inflammatory biomarkers in dairy heifer calves.

\section{Materials and Methods}

All animal procedures were approved by the Iowa State University Institutional Animal Care and Use Committee. The study was conducted from June 16 to July 10 of 2020 at Iowa State University dairy farm (Ames, IA). Nine Holstein and 2 Jersey heifer calves $(n=11)$ at 5 to 6 months of age were used. Calves were housed in individual stalls (floor area $=4.57 \mathrm{~m} \times 2.28 \mathrm{~m}$ ) bedded with corn stover in the Iowa State University maternity barn, where inside temperature were controlled. Individual calves had free access to ad libitum amounts of clean drinking water and a total mixed ration (meeting or exceeding the predicted NRC-2001 requirements) in two separate plastic buckets throughout the study. The experiment included 3 periods. During the first period (P1), the barn temperature was equilibrated with outside environmental temperature $\left(\begin{array}{ll}7 & \mathrm{~d}\end{array}\right)$ and baseline measurements obtained. Following P1, calves were subjected to a $7 \mathrm{~d}$ diurnal heat stress bout (P2), where inside temperature of the barn was set to $35^{\circ} \mathrm{C}\left(95^{\circ} \mathrm{F}\right)$ from 0900 to $2100 \mathrm{~h}$ on a daily basis. The barn temperature was

Copyright (C) 2021 by the Authors. This is an open access article published under the CC BY-NC license (https://creativecommons.org/licenses/by-nc/4.0/), which allows for non-commercial reuse with proper attribution. 
equilibrated with the environmental temperature from 2100 to $0900 \mathrm{~h}$ daily (P2). Following the heat stress bout, calves were allowed to recover over $4 \mathrm{~d}$, while the barn temperature was equilibrated with the environmental temperature (P3).

Feed and drinking water intake $(\mathrm{kg} / \mathrm{d})$ of individual calves were recorded daily throughout the study. Feed intake specifically between 0900 and $2100 \mathrm{~h}$ were recorded on the last day of P1, and throughout P2 and P3. Body weight of individual calves were recorded at the beginning and end of each period. Heart rate (HR), respiratory rate (RR), rectal temperature (RT), and skin temperature on the neck (ST) were recorded twice daily (1300 and $1800 \mathrm{~h}$ ) on the last day of P1, day 1, 3, and 7 in P2, and day 4 in P3. Rectal temperature and ST were measured using a standard digital thermometer and an infrared thermometer, respectively. Respiration rate was determined by counting flank movements, and HR was determined using a stethoscope placed over the left side of the rib cage behind the elbow. Following vital collections, blood samples were collected at $1500 \mathrm{~h}$ via the jugular vein and were centrifuged at $1,500 \times \mathrm{g}$ for $15 \mathrm{~min}$ at $4^{\circ} \mathrm{C}$ and stored at $-20^{\circ} \mathrm{C}$ before analysis. Blood was later analyzed for haptoglobin, lipopolysaccharide binding protein (LBP) and cortisol concentrations using commercial kits. Ambient temperature $\left({ }^{\circ} \mathrm{C} /{ }^{\circ} \mathrm{F}\right)$ and relative humidity were monitored and recorded using portable data loggers with USB interface. Computed average day (0900 and $2100 \mathrm{~h}$ ) and night temperatures of P1, P2 and P3 were 28.1, 33.1 and $29.4{ }^{\circ} \mathrm{C}$, and $24.9,23.9$ and $23.6^{\circ} \mathrm{C}$, respectively. Moreover, corresponding THI (temperaturehumidity index) values were 79, 85 and 80, and 75, 73 and 73 , respectively.

All the data were analyzed using the MIXED procedure of SAS with repeated option to test the fixed effects of period (P1, P2, and P3) or specific sampling days of each period, with animal as the random effect. Results are reported as least squares means and were considered different when $P \leq 0.05$ and a tendency if $0.05<P<0.10$.

\section{Results and Discussion}

Compared to baseline (P1), RT, ST and RR increased, $0.8^{\circ} \mathrm{C}, 1.0^{\circ} \mathrm{C}$ and $45 / \mathrm{min}$, respectively, on the first day of heat stress (P2, Table 1). Those parameters remained elevated until the end of P2 and returned to baseline levels $4 \mathrm{~d}$ after (P3). Even though HR increased significantly on the first day, it returned to baseline level as of the third day of P2. Nonetheless, RT, ST, RR, HR along with aforementioned THI attest that calves experienced significant hyperthermia in P2. Persistently high RT, ST, and RR in P2 also indicate no acclimation during the heat stress bout.

Calves consumed less DM during the daytime in P2 (0900 to $2100 \mathrm{~h}$ ), compared to corresponding DMI in P1 (Figure 1). On the other hand, they consumed more DM during nighttime making total DMI similar between P1 and P2. During the recovery period, DMI during the daytime increased and became similar to that of P1. However, calves continued to have high DMI during night resulting in a greater total DMI in P3 compared to P1 and P2 (Figure 1). Even though total
DMI was similar between $\mathrm{P} 1$ and $\mathrm{P} 2(P=0.995)$, average daily gain (ADG) decreased significantly during P2 compared to $\mathrm{P} 1(0.28$ vs. $1.28 \mathrm{~kg} / \mathrm{d})$ indicating substantially elevated maintenance requirement of nutrients, which was also reflected in lower gain to feed ratio (Table 2) in P2 compared to P1. Relative to P2, ADG increased markedly in P3 $(P<0.001)$. Interestingly, ADG in P3 tended to exceed that in P1 $(2.04$ vs. $1.28 \mathrm{~kg} / \mathrm{d})$ indicating a substantial compensatory growth, which was possibly supported by the elevated DMI. As expected, calves consumed more drinking water per unit of DMI during heat stress compared to the baseline period (8.47 vs. $5.94 \mathrm{~kg} / \mathrm{kg}$ of DMI, $P<0.001$, Table 2). Interestingly, calves continue to consume more drinking water relative to DMI even after heat stress had been ceased, highlighting the importance of drinking water in recovery from heat stress.

Serum haptoglobin concentrations is often used to assess inflammation and disease status in calves as immune activation has been shown to increase serum haptoglobin more than 100-fold. In the present study, calves had significantly higher serum haptoglobin concentrations on $\mathrm{d} 3$ of dHS relative to P1 $(P=0.008$, Figure $2 \mathrm{~A})$. Similarly, LBP and cortisol concentrations also increased numerically on day 3 in P2 (Figure 2B and C) suggesting immune activation via impaired gut barrier function. However, those concentrations returned to baseline levels by the end of the heat stress bout (Figure 2). Nevertheless, the activated immune system can utilize a significant amount of energy (i.e., glucose) and protein partly contributing to the elevated maintenance requirements of nutrients during heat stress.

\section{Conclusions}

Diurnal hyperthermia was successfully induced in 5-6 months old calves by maintaining barn temperature at $33.1^{\circ} \mathrm{C}$ $\left(91.5^{\circ} \mathrm{F}\right)$ during 0900 to $2100 \mathrm{~h}$ for $7 \mathrm{~d}$. Dry matter intake decreased during hyperthermia but calves compensated by consuming more feed during night. Nonetheless, ADG and feed efficiency significantly decreased during the heat stress bout indicating that calves spent a substantial amount of nutrients to combat heat stress. The elevated haptoglobin levels in blood indicates an immune activation likely repartitioned nutrient away from productive processes during heat stress. Nonetheless, calves exhibited compensatory growth post hyperthermia, which was associated with increased DMI and increased drinking water intake per unit of DMI.

\section{Acknowledgement}

We acknowledge the support received from the staff in Dairy Research and Teaching Farm at Iowa State University. 
Table 1. Least squares means and the statistical significance of heart rate (HR), respiratory rate (RR), rectal temperature (RT) and skin temperature (ST) of dairy heifer calves $(\mathrm{n}=11)$ prior to, during and $4 \mathrm{~d}$ after a $7 \mathrm{~d}$ diurnal heat stress bout.

\begin{tabular}{|c|c|c|c|c|c|c|c|}
\hline \multirow{2}{*}{ Variable } & \multirow{2}{*}{$\begin{array}{l}\text { Baseline } \\
\text { (P1) }\end{array}$} & \multicolumn{3}{|c|}{ Diurnal heat stress bout (P2) } & \multirow{2}{*}{$\begin{array}{l}\text { Recovery } \\
\text { (P3) }\end{array}$} & \multirow{2}{*}{ SEM } & \multirow{2}{*}{$P$-value } \\
\hline & & Day 1 & Day 3 & Day 7 & & & \\
\hline $\mathrm{HR}, / \min$ & $92.18^{\mathrm{a}}$ & $102.18^{\mathrm{b}}$ & $97.09^{\mathrm{ab}}$ & $90.36^{\mathrm{a}}$ & $98.60^{\mathrm{ab}}$ & 2.40 & 0.007 \\
\hline $\mathrm{RR}, / \mathrm{min}$ & $77.45^{\mathrm{a}}$ & $123.09^{\mathrm{b}}$ & $125.27^{\mathrm{b}}$ & $128.55^{\mathrm{b}}$ & $107.82^{\mathrm{c}}$ & 3.43 & $<0.001$ \\
\hline $\mathrm{RT},{ }^{\circ} \mathrm{C}$ & $39.38^{\mathrm{a}}$ & $40.22^{\mathrm{b}^{*}}$ & $40.51^{\mathrm{b}}$ & $40.18^{b \neq}$ & $39.63^{a^{* \neq}}$ & 0.28 & $<0.001$ \\
\hline $\mathrm{ST},{ }^{\circ} \mathrm{C}$ & $35.30^{\mathrm{a}}$ & $36.28^{\mathrm{b}}$ & $36.24^{\mathrm{b}}$ & $37.83^{\mathrm{c}}$ & $35.92^{\mathrm{ab}}$ & 0.19 & $<0.001$ \\
\hline
\end{tabular}

a-c Within row statistical differences for each predictor variable; $P<0.05 .{ }^{*}$ Within row statistical differences for each predictor variable; $0.05<P<0.10$.

Table 2. Least squares means and the statistical significance of average daily gain (ADG), dry matter intake (DMI), drinking water intake (FWI), FWI: DMI and gain: feed ratio (ADG: DMI) of dairy heifer calves $(\mathrm{n}=11)$ prior to, during and $4 \mathrm{~d}$ after a 7 d diurnal heat stress bout.

\begin{tabular}{|c|c|c|c|c|c|}
\hline Variable & $\begin{array}{l}\text { Baseline } \\
(\mathrm{P} 1)\end{array}$ & $\begin{array}{c}\text { Diurnal heat stress } \\
(\mathrm{P} 2)\end{array}$ & $\begin{array}{l}\text { Recovery } \\
\text { (P3) }\end{array}$ & SEM & $P$-value \\
\hline $\mathrm{ADG}, \mathrm{kg} / \mathrm{d}$ & $1.28^{\mathrm{b}}$ & $0.28^{\mathrm{a}}$ & $2.04^{\mathrm{b}}$ & 0.27 & $<0.001$ \\
\hline DMI, kg/d & $5.49^{\mathrm{a}}$ & $5.47^{\mathrm{a}}$ & $6.56^{\mathrm{b}}$ & 0.23 & 0.006 \\
\hline FWI, kg/d & $33.85^{\mathrm{a}}$ & $45.39^{b}$ & $49.30^{\mathrm{b}}$ & 1.78 & $<0.001$ \\
\hline FWI: DMI & $5.94^{\mathrm{a}}$ & $8.47^{\mathrm{b}}$ & $7.76^{\mathrm{b}}$ & 0.38 & $<0.001$ \\
\hline Gain: feed & $0.22^{\mathrm{b}}$ & $0.06^{\mathrm{a}}$ & $0.31^{\mathrm{b}}$ & 0.04 & 0.002 \\
\hline
\end{tabular}

${ }^{\mathrm{a}, \mathrm{b}}$ Within row statistical differences for each predictor variable; $P<0.05$.

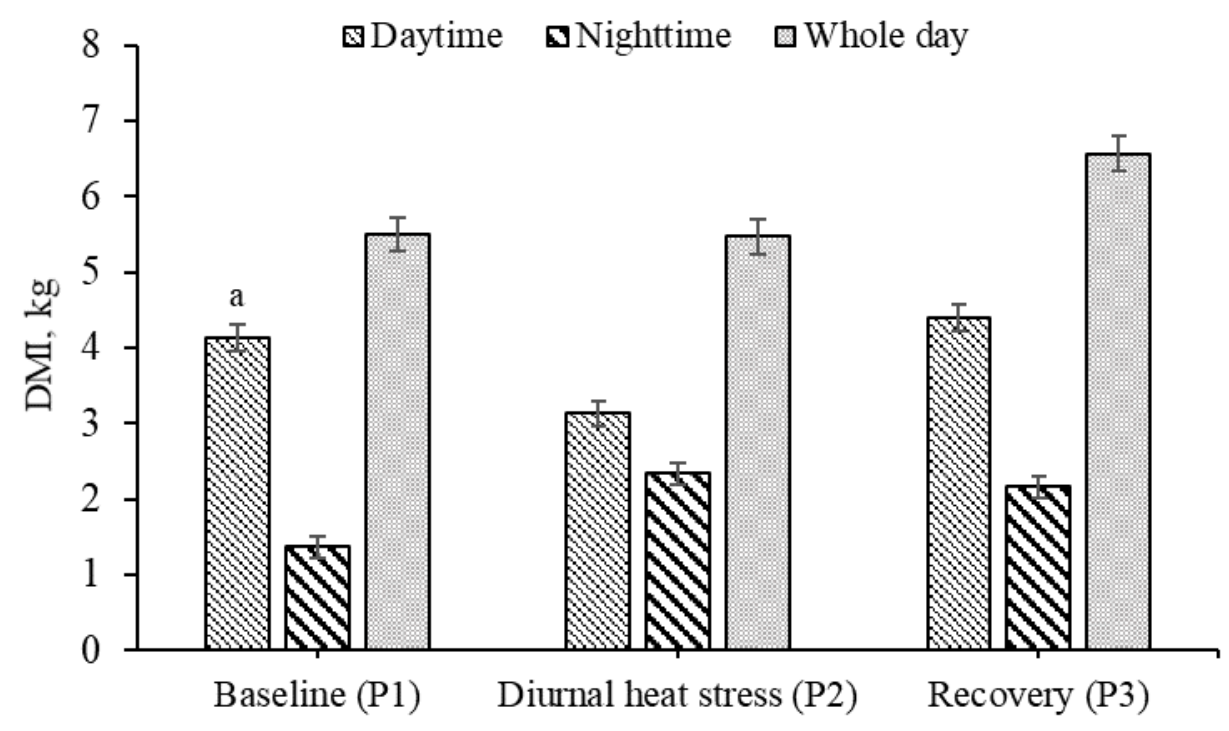

Figure 1. Least squares means and the statistical significance of dry matter intake (DMI) of dairy heifer calves $(\mathrm{n}=11)$ prior to, during and 4 days (d) after a $7 \mathrm{~d}$ diurnal heat stress bout. Daytime represents (0900 - 2100) hours and nighttime represents (2100 - 0900) hours in each period, respectively. ${ }^{\mathrm{a}-\mathrm{b}}$ Different letters on columns with similar pattern (corresponding to time period) indicate statistical differences $(P<0.05)$. 

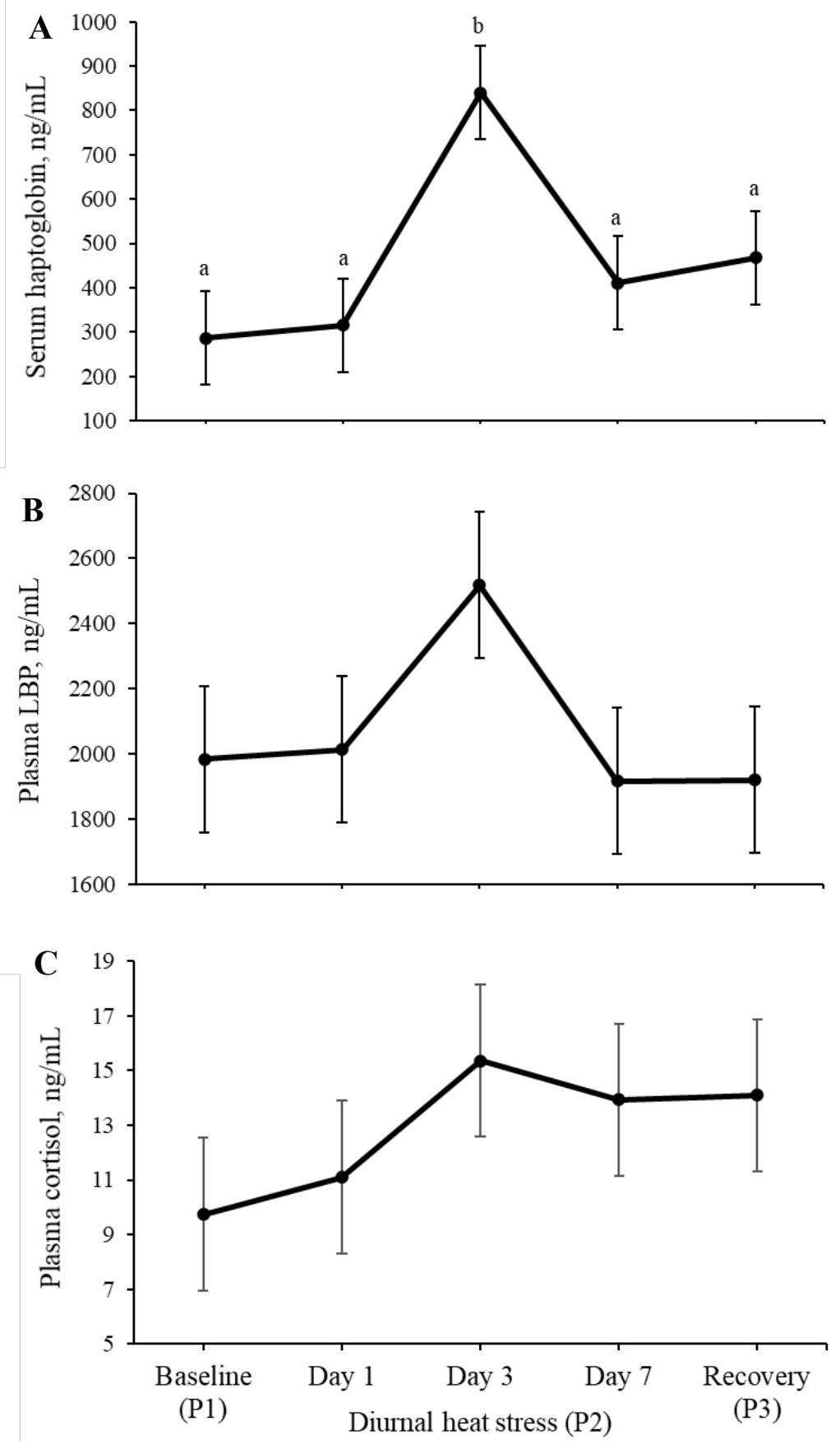

Figure 2. Least squares means \pm SEM of serum haptoglobin (A), plasma lipopolysaccharide binding protein (LBP) (B) and plasma cortisol concentration $(\mathbf{C})$ of dairy heifer calves $(\mathrm{n}=11)$ prior to, during and 4 days $(\mathrm{d})$ after a $7 \mathrm{~d}$ diurnal heat stress bout. ${ }^{\mathrm{a}-\mathrm{b}}$ Statistical differences for each predictor variable indicating significance $(P<0.05)$. 